\title{
Study on the Evolution Mechanism of Urban Flood Disaster Social Risk Based on the Model of Four Dimensions of Social Amplification of Risk
}

Qian Sun, Xuanpeng Yin, Jing Cao

中南大学商学院, 长沙 410083, 中国

\section{基于四维社会放大模型的城市特大内港灾害社会 风险演化机理研究}

孙倩, 尹儇鹏, 曹静

中南大学商学院, 长沙 410083 , 中国

\begin{abstract}
Aiming at the problem that social stability and order is often seriously threatened by urban flood disasters, a four dimensions model of social amplification of urban flood disaster social risk amplification in Chinese transforming society is proposed on the basis of the theory of social amplification of risk. And then we analyzed the amplification mechanism of urban flood disaster risk. Besides, we studied the evolution mechanism of urban flood disaster risk evolving from individual risk to group events and then to social risk. Furthermore, we applied the amplification and evolution mechanism to the case study of Zhejiang Yuyao flood social risk. Finally, some advices are put forward to respond to urban flood disaster risk.
\end{abstract}

Keywords: Urban flood disaster; Social risk; Risk amplification; Evolution mechanism

\section{摘要}

针对城市特大内涝灾害发生后社会稳定与秩序 受到严重威胁问题，本文利用风险的社会放大 理论构建了中国社会转型背景下城市特大内涝 灾害社会风险四维放大模型, 分析了城市特大 内涝灾害风险的放大机制, 并在此基础了研究 了城市特大内涝灾害风险如何由个体风险演化 为群体性事件, 进而演化为社会风险的机理。 此外, 将风险的放大机制和演化机理应用到浙 江余姚城市特大内涝社会风险案例剖析中。最 后, 提出了城市特大内涝灾害社会风险应对建
议。

关键词: 城市内涝灾害; 社会风险; 风险放大; 演化机理

1. 引言

近年来, 随着台风、暴雨等极端气象灾害 频发与城市化进程的不断加快, 城市内涝已成 为影响城市发展的首要问题。2011 年住房和城 乡建设部对全国 351 个城市内涝情况进行调 查, 发现 2008 至 2010 年间多达 $62 \%$ 的城市遭 受不同程度内涝 ${ }^{[1]}$ 。另据民政部统计 2013 年我 国各类自然灾害中城市内涝灾害影响尤为突出 ${ }^{[2]}$ 。这些灾害不仅直接导致了人员伤亡和经济 损失, 同时也给受灾群众带来了深远的心理影 响 $^{[3]}$ 。此外, Tierney $K \mathrm{~J}^{[4]}$ 认为灾害会经常伴 随着社会团结和社会冲突问题, 而且性别、种 族等不平等问题会进一步加剧社会冲突。Ne1 P 和 Righarts $\mathrm{M}^{[5]}$ 对 187 个政治单元(political units）1950-2000 年间的统计资料分析发现， 自然灾害在一定程度上会增加暴力冲突事件风 险, 尤其是在政治制度混杂、不平等问题突出 的中低收入国家。针对自然灾害是否会引发政 治不稳定性, Omelicheva M $\mathrm{Y}^{6]}$ 运用冲突模型进 行探讨发现, 政治体制特点和危机应对能力起 决定性作用, 自然灾害在有社会冲突的国家往 往会成为政治不稳定的催化剂。Hsiang $S \mathrm{M}^{[7]}$ 也用定量研究证明了气候变化与冲突之间存在 一定关系。人类对气候引起的压力事件的反应 往往表现为示威抗议、社会骚乱、政治攻击及 国家镇压 (state repression) 等形式 ${ }^{[8]}$, 严 重冲击着社会的稳定与秩序。2013 年浙江省余 


\section{Risk Analysis and Crisis Response in Big Data Era (RAC-16)}

姚市受 “菲特” 台风影响, 遭遇特大内涝灾害, 引发了物资哄抢、警民冲突、围堵市政府等群 体性事件, 对当地政治稳定与社会秩序构成了 重大潜在社会风险。

目前许多学者对城市内涝问题的现状、形 成原因及应对措施进行了大量研究, 大多认为 城市内涝问题是城市建设不合理的后果, 提出 的应对措施多是如何减小内涝灾害发生次数 ${ }^{[9-11]}$ 。但这些研究仅分析了城市内涝的形成原 因, 缺乏特大内漟发生后对社会稳定与秩序等 社会深层次影响的研究, 更少有学者研究城市 特大内涝灾害从自然灾害放大为社会风险的机 制和路径。

此外，我国目前正处于社会转型时期，旧 的社会制度与规范失效, 而新的社会制度和规 范尚未成熟, 社会处于一种失范状态 ${ }^{[12]}$, 社会 经济发展不平衡, 贫富差距进一步拉大, 社会 阶层分化严重, 容易引起社会弱势群体的不满 情绪, 这种不满情绪在一定突发事件的诱发下 会成为破坏性的社会危机 ${ }^{[13]}$ 。中国社会转型使 得各种社会矛盾呈现出叠加效应, 转型本身就 是风险之源, 呈现出高风险社会特征。而城市 特大内涝灾害的发生给弱势群体造成了巨大的 经济和心理压力, 会激发他们的不满情绪, 产 生一些过激行为风险, 与社会转型风险交叉耦 合, 对社会的稳定与秩序会构成巨大威胁。而 且中国社会转型是其他国家发展进程中没有 的, 具有浓厚的中国社会本土特色, 已有的国 外社会风险的研究并不能有效分析中国社会转
型背景下的城市特大内涝灾害社会风险, 同时 很少有研究探讨社会转型风险与城市特大内涝 灾害风险如何在互动中实现风险的放大与演 化。为此, 有必要探讨中国社会转型背景下城 市特大内涝灾害社会风险的放大机制与演化机 理, 为有效阻断或控制局部性风险演化为社会 危机有着重要的现实意义。

\section{2. 风险的社会放大理论}

传统风险分析中最复杂的问题是一些被技 术专家评估为相对较小的风险或风险事件经常 会引发强烈的社会关注并对社会和经济等产生 一系列影响; 而技术专家评估为较大的风险却 不受关注。针对这一问题 Roger E. Kasperson 及其同事将风险的技术评估与心理、社会、文 化等社会因素联系起来, 构建了风险的社会放 大基本框架 ${ }^{[14]}$ (The Social Amplification of Risk: A Conceptual Framework, SARF)。

该理论认为信息过程、制度结构、社会群 体的行为和文化会与风险事件相互作用, 这种 社会相互作用会加强或减弱有关风险的信号及 行为反应, 导致风险事件产生次级影响。这些 次级影响远远超过了风险事件对人类或环境的 直接影响, 会波及到其他领域和地域, 导致更 为广泛的 “涟渏效应”。此外, 每级影响不仅对 社会和政治产生影响还可能引发新风险甚至会 阻碍风险应对。Kasperson 将这种现象描述为 风险的社会放大, 并用图 1 所示的框架说明了 风险社会放大的过程。

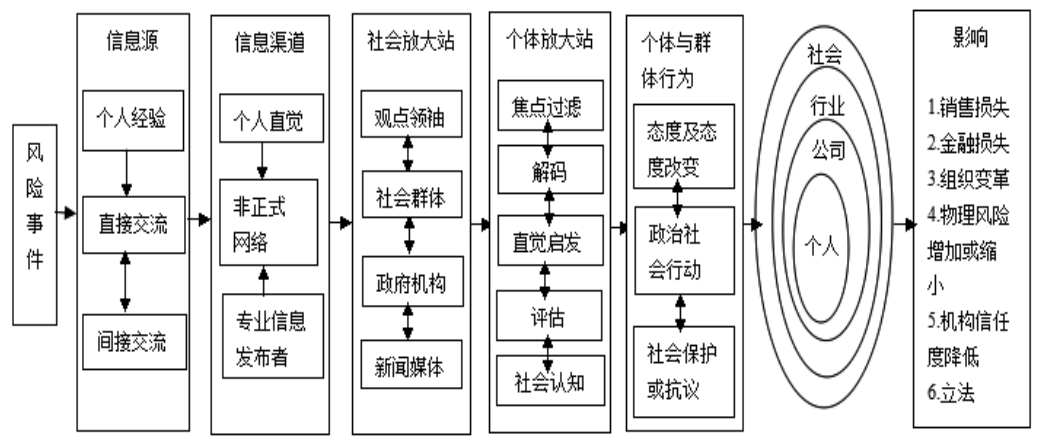

图 1. 风险的社会放大理论框架

风险的社会放大过程开始于风险事件, 人 们根据已有的经验和心理机制对风险事件进行
选择性解读、加工并传播给其他社会群体, 社 会群体根据接受到的风险信息进行评估, 产生 
Risk Analysis and Crisis Response in Big Data Era (RAC-16)

一些行为反应。以上过程中信息的传播和社会 群体反应是导致风险社会放大的两个主要阶 段。信息传播过程中有关风险信息的报道量、 信息的争议度、信息的戏剧化程度、信息所包 含的象征隐喻和沟通渠道将会通过两个途径放 大风险: 一是改变个体和群体接受到的风险信 息; 二是影响人们对信息的过滤。社会响应机 制主要通过四种方式放大风险: 一是个体简单 的风险反应; 二是社会群体和政治群体观点影 响后作出反应; 三是根据风险信号值做出反应; 四是污名化现象下的评估和反应。

SARF 解释了风险事件在社会相互作用下 被社会群体关注或忽略的原因, 目前已广泛应 用到热浪、火山云、森林火灾等 ${ }^{[15-17]}$ 风险事件 放大或缩小的研究中, 为研究城市内涝灾害社 会风险放大奠定了理论基础。

\section{3. 城市特大内涝灾害社会风险演化机理}

\section{1. 基于 SARF 的城市特大内涝灾害社会风险} 四维放大模型构建

城市内涝灾害是自然因素造成的,一般没 有直接负责人，但当伤亡人员较多、基本生活 条件严重破坏时人们就会抱怨预警信息不准 确、不及时和政府部门救灾不力, 甚至做出非理 性行为, 如群体上访、围攻政府等, 这些行为又 会作为一种风险信号被更多社会群体所感知 到, 产生 Kasperson 所描述的涟渏效应。由此 可见, 城市特大内涝灾害事件在各种社会因素 相互作用下产生的影响会远远超过灾害本身对 人类和自然环境的直接伤害, 有可能演化成为 群体性事件甚至是具有社会属性的社会危机, 是一种典型的风险社会放大。Kasperson 所构
建的 SARF 能够简单阐述城市特大内涝灾害社 会放大的两个维度：信息传递和公众反应。但 我国有着特殊的国情, 政府是应对灾害事件的 主体, 完全承担了灾害信息的发布、灾害救援及 灾后补偿工作, 作为单一主体应对灾害事件模 式基本没有变 ${ }^{[18-19]}$, 受灾群众主要依赖于政府, 对政府信任度的高低在很大程度上决定了受灾 群众的风险认知水平, 进一步决定了群众的风 险行为。因此, 政府这一特殊组织是我国风险 社会放大中最为重要的一个维度, 有必要单独 分析其对城市特大内涝灾害社会风险放大的作 用机制。

另外, 中国正处于社会转型环境, 具有高 脆弱性和风险性社会的特征, 一些弱势群体应 对自然灾害的能力较低, 同时面临健康、生存、 食物冲突等各种风险事件, Scheffran $\mathrm{J}^{[20]}$ 认为 如果气候变化增加人们已经面临的风险, 气候 变化就会增加人道危机甚至激发潜在冲突, 使 得城市特大内涝灾害从一种自然灾害演化为社 会风险事件。同时, 社会转型时期社会群体对 各种风险事件具有敏感性, 灾后处于相同的环 境, 容易达成心理共识, 社会冲突发生后社会 群体容易以集体化、规模化的形式对抗，导致 风险的叠加与集聚放大。由此可见, 我国社会 转型这一特殊环境不仅是城市特大内涝社会风 险爆发的肥沃土壤也会与其在互动中实现放 大。所以, 社会转型环境是城市特大内涝灾害 放大与演化过程中的一个重要维度, 需要进一 步探讨两者的相互作用机制。因此, 本文根据 SARF, 结合以上分析的中国政府应急模式和中 国转型的特点构建了城市特大内涝灾害的四维 度的社会风险放大模型如图 2 所示。



图 2. 中国城市特大内涝灾害社会风险四维放大模型 


\section{Risk Analysis and Crisis Response in Big Data Era (RAC-16)}

(1) 第一维度的灾害风险放大: 城市特大 内涝灾害发生后，有关灾害情况的各种信息铺 天盖地，既有来自政府部门的官方报道，也有 来自互联网、人际关系网络和各种非官方媒体 的信息。灾害信息会在这些 “放大站” 根据信 息传播者自身的理解被加工、删除或放大，在 一定程度上导致信息失真。随着信息的不断强 化和传播, 城市特大内涝灾害风险的严重性会 被放大，从而使人们形成高风险认知，构成城 市内涝灾害风险的第一轮放大。

(2) 第二维度的灾害风险放大: 在一个日 益复杂的社会世界里，人们不可能完全了解他 们所面临的所有威胁。因此, 他们被迫需要信 任某些科学专家、政府等权威机构。这些信任 会减少人们对灾害风险的不确定性, 但当人们 对专家或权威机构不信任或信任被破坏时人们 就会面临更高的风险认知 ${ }^{[21-23]}$ 。因此, 社会群 体对政府等权威机构信任缺失时将会提高人们 的风险认知, 进而导致风险的第二轮放大。此 外, 当人们对政府部门的应急管理能力十分信 任时，人们就会过度依赖政府。Bichard 和 Kazmierczak $^{[24]}$ 发现大多数人认为防灾和灾后 救援是政府部门的责任, 政府部门必须采取保 护措施来减轻人们的灾后负担。因此, 在这种 情形下, 如果政府等权威机构救灾不力, 受灾 群众就会产生不满情绪、甚至对政府部分采取 过激行为, 直接导致灾害风险演化为群体性事 件。由此可知, 政府等权威机构应对灾害的能 力和态度会通过信任度影响风险认知, 决定风 险走向, 构成风险的第二轮放大。

(3) 第三维度的灾害风险放大: 根据风险
-信息-行为理论, 当人们意识到事件或灾害有 风险时, 人们就会搜集相关信息, 在已有经验 基础上形成风险认知并做出一些降低风险的行 为。在前两轮的风险放大下, 人们往往会形成 高风险认知, 在高风险认知下, 风险的严重性 被放大, 人们往往会产生恐慌心理、失去理智, 采取各种非理性行为或过激行为, 而这些过激 行为又被作为一种信号源传播出去, 影响更广 受灾群众, 直接导致风险演化, 形成灾害风险 的第三轮放大。

(4) 第四维度的灾害风险放大: 在中国特 殊的社会转型时期, 存在着贫富差距较大和社 会保障体系不完善的问题, 社会弱势群体存在 着强烈的利益诉求和不满心理，人们内部之间 存在一定矛盾, 社会本身就处于一种风险社会 状态, 各种风险事件一触即发。而城市内涝灾 害导致大量人员伤亡和经济损失的城区往往是 城市发展落后的地区, 在社会经济系统异常脆 弱情况下, 城市特大内涝灾害会引发食品短缺、 安置困难、流行病爆发等严重后果 ${ }^{[25]}$, 社会中 被压抑的情绪和失衡的心理被点燃, 导致灾害 风险的第四轮放大。

\section{2. 城市特大内港灾害社会风险演化机理}

根据城市内涝灾害社会风险四维度放大模 型可知, 城市特大内涝灾害在信息传播、公众 反应、政府信任度、社会转型环境四个维度下 会不断放大为社会风险, 产生 “涟渏效应” 并 遵循由城市特大内涝灾害本身演化为个体风 险, 然后个体风险又演化为群体风险, 进而转 化为社会风险的机理, 如图 3 所示。

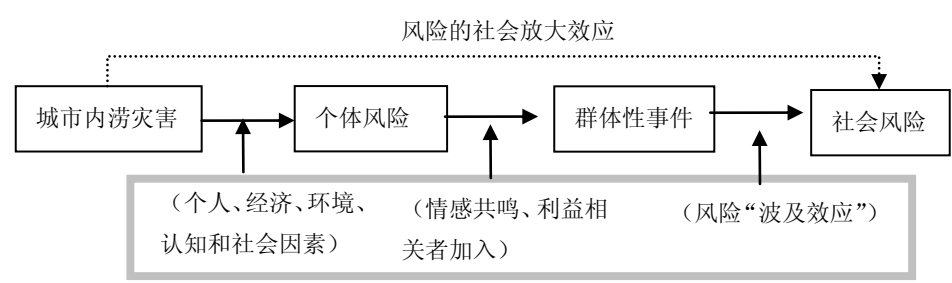

图 3. 城市内涝灾害社会风险演化机理图

\section{第一阶段：城市特大内港灾害演化为个体 风险}

城市特大内港灾害的发生将导致房屋倒
塌, 人员伤亡, 电力、通信、道路等基础设施 严重受损。这一方面使受灾群众的衣食住行受 到了严重影响, 灾害发生后人们比较恐慌, 有 
Risk Analysis and Crisis Response in Big Data Era (RAC-16)

较强的压力感。根据压力-状态-响应理论, 城 市内港灾害使受灾群众有较大的生存及心理压 力, 受灾群众处于一种悲伤、无助的状态下, 在这种状态下个体在生理上会有呼吸急促、警 惕性提高等症状, 这将作为一种风险信号被个 体意识到, 个体对灾害往往会评估为较高的风 险。在高风险认知下, 个体行为会失去理性, 做出一些极端行为。比如, 有些受灾群众情绪 比较激动很容易和别人争吵, 甚至会有肢体冲 突; 有些人因不能及时得到救援物资而进行哄 抢、对政府救灾不满而产生抱怨情绪。综上所 述, 极端气象灾害发生会使个体面临生理、情 绪和行为风险

\section{第二阶段：个体风险演化为群体性事件}

根据 SARF，社会群体的行为反应将会产生 风险的第二轮放大, 导致一些个体事件演化成 为群体性事件。这是由于灾害发生后个体事件 的发生往往是受灾群众对自身安危和切身利益 诉求的结果, 受灾群众之间很容易产生情感共 鸣, 盲目地加入到小规模集群行为中。此外, 城市特大内涝灾害利益诉求一般包含了对政府 救灾能力的巨大社会信任, 并且根植于我国特 定的社会转型背景中, 新的利益诉求和历史长 期积累的隐患交织在一起。如果政府救灾不力, 受灾群众往往会有抗议、群体性上访等过激行 为。这些过激行为经过信息传播过程的加工和 放大, 风险事件就会放大, 被更多的直接利益 相关者和潜在相关者所认同, 并作为社会转型 时期已有社会矛盾的 “点燃剂”, 将局部的个体 风险转化为群体性事件。

\section{第三阶段：群体性事件演化为社会风险}

群体性事件具有突发性, 短时间内参与人 员情绪比较激动、其行为失去约束性, 往往会 做出过激行为或违法行为。如果政府只是利用 警力和警械对参与人员进行管制的话，人的生 命安全受到威胁而得不到保护, 人们就会更加 愤怒, 采取更极端的行为, 甚至会产生暴力冲 突。这些行为对当地的社会稳定与秩序构成巨 大的威胁, 导致公共信任制度和应急管理机构 应急能力满意度和认同度的急剧下降, 引起社 会群体风险认知和风险态度的长期变化, 社会 秩序制度的建设与完善，一般会产生较大的社 会和政治压力。此外, 这些群体性事件的次级 影响又将作为一种风险信号被更多社会群体感
知到, 产生更高级的影响。这种 “波及效应” 会影响到其他地区、其他领域甚至国际范围。

\section{4. 菲特台风造成浙江余姚特大内港社会风险 放大与演化案例剖析}

我国是城市内涝灾害发生最频繁的国家之 一, 为了研究城市特大内涝灾害与社会风险的 演化关系, 本文对菲特台风造成的浙江余姚特 大内港进行了相关分析。2013 年 10 月 7 日第 23 号强台风 “菲特” 在福建省登陆, 让多地饱 受洪涝之苦, 其中浙江余姚受灾最为严重, 遭 遇了百年罕见降雨, $70 \%$ 以上城区受淹, 受灾人 口 832870 人, 房屋受损 25650 间, 转移人口 61665 人, 余姚全市直接经济损失达 69.91 亿

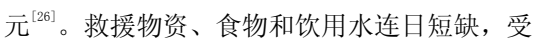
灾群众饥肠辘辘、难以忍耐, 受灾群众小章购 买救援物资不成便开始抢, 然后从口头争吵变 为肢体冲突, 将皮划艇上的 30 箱饼干散落在水 中, 周围的人一哄而上, 将物资全部抢走 ${ }^{[27]}$ 。 在这特殊时期, 身为抗灾总指挥的毛宏芳却发 表冷血言论称 “灾难期间, 能吃上就不错了”, 自夸抗灾表现 60 分。11 日余姚民众因指责当 地电视台粉饰灾情, 将采访车围堵, 多辆警车 被砸坏并掀翻。10 月 15 日余姚近万市民在市 政府门前聚集, 不满意当局救灾力度、抗议官 员为粉饰太平而发表荒谬言论, 要求市委书记 毛宏芳下台。有示威者向政府大楼投郑石头, 也有人砸车泄愤, 场面相当混乱。当局紧急调 派大批警员到场维稳, 并爆发冲突 ${ }^{[28]}$ 。此后, 多家报纸、媒体对余姚群体性事件进行了大量 报道，一段时间内成为公众关注的焦点。

从浙江余姚洪灾事件的演化轨迹来看, 事 件引起的本身原因是台风造成的百年不遇特大 暴雨造成城市特大内涝, 是一场自然灾害事件。 按常理, 受灾群众应该全身心地投入到抗灾救 援及灾后重建工作中。但是在各种信息的传递、 部分受灾群众的过激行为、政府官员不负责的 言论以及弱势群体的借机宣泄原有不满情绪的 情况下, 从一场自然灾害不断放大演化为群体 性事件, 最终对当地的社会稳与秩序造成了重 大的威胁。我们根据构建的城市特大内涝灾害 社会风险四维放大模型和演化机理对浙江余姚 城市内涝社会风险进行分析与解释。 


\section{Risk Analysis and Crisis Response in Big Data Era (RAC-16)}

\section{（1）网络互动, 人际交流, 信息失真}

和放大与信息传播有着直接的关系。宁波 电视台对灾区进行报道时称 “一些道路积水已 退去, 有些路段是趟着水进去的” 时, 有些受 灾严重的灾民认为报道情况与自己实际情况不 符, 并打电话叫人过来, 同时围观的群众拍照 发微博称 “记者在现场说余姚灯火通明, 记者 骂余姚人是神经病”。个别受灾群众根据自己的 理解对信息的解读并通过微博和电话等形式传 播出去, 导致信息失真。被扭曲的信息点燃了 受灾群众不满情绪和心中的怒火, 做出一些非 理性行为 (围观直播车、谩骂、威胁), 利益诉 求引发周围群众共鸣, 直接导致个别事件演化 为群体事件, 此为风险的第一轮放大。

\section{（2）政府信任危机}

“菲特”台风发生时政府部门虽然通过手 机短信向广大群众发布了预警信息, 但是对这 次灾情估计不足, 预警信息发布具有滞后性, 部分灾民认为预警信息是马后炮。同时，一些 被困群众买点花生白菜需要数百元、裹着报纸 过夜, 并不清楚去哪领取救援物资, 政府救灾 应急能力遭受质疑 ${ }^{[29]}$, 群众对政府的信任度急 剧下降。群众情绪失控, 因而引发近万市民在 政府门前聚集，场面混乱，当地政府以劝导和 调动警力方式压制社会矛盾，进一步激发了受 灾群众恐慌、不满情绪, 当地社会稳定与秩序 收到严重威胁, 对社会和政治形成了较大压力。 从而导致了风险的第二轮放大, 使得群体事件 演化为社会风险。

（3）个体过激行为及政府官员不负责言 论行为

浙江余姚个别群众的非理性行为和政府的 不负责言论是导致群体上访、群体过激行为的 直接驱动因素。在救援物资发放过程中, 物资 发放人员没有将物资卖给小章, 小章不满将救 援物资抢走的行为会传染给周围的群众。根据 社会学研究, 群体心理有两个比较明显的特征 就是情绪传染和行为模仿, 由于小章抢到了物 资, 周围人群会模仿这种行为, 从而导致群体 哄抢物资。一旦某个个体采取了一些过激行为, 由于情绪和行为传染及法不责众心理, 周围人 群的情绪就被点燃，参与到打砸警车、围攻政 府的行为中来宣泄不满情绪, 导致风险放大, 事件升级。此外, 本案例中政府官员的不负责
言论也是激发群众过激行为的风险源, 在食物 短缺、安置困难情况下, 市委书记却发表灾难 太突然, 神仙也救不了的言论, 群体不满情绪 瞬间转化为行为实施, 这种行为得不到有效缓 解, 就会演变为严重的社会冲突 ${ }^{[30]}$, 此为风险 的第三轮放大, 个体事件演化为群体事件。

（4）社会转型环境下社会脆弱性与风险 性

社会转型给中国带来了很多好处, 但也存 在很多问题。一方面, 社会转型导致领域间的 关系是一种网状结构关系, 关联度较大。余姚 发内涝时电力系统的㿈瘾影响到交通、供水系 统、企业生产等多个行业, 使得间接经济损失 大于直接经济损失, 增加了灾害损失和社会脆 弱性。另一方面, 社会转型最突出的特点就是 发展不平衡导致社会不公平现象蔓延, 这加剧 了不同利益主体之间的矛盾与冲突, 社会处于 风险状态 ${ }^{[31]}$ 。余姚受灾严重的往往是那些外来 人员和经济收入较低的弱势群体, 灾后存在较 大的生存压力, 这种压力引发了人们原有一些 失衡心理的发泄, 做出一些非理性行为, 将灾 害直接伤害转化为个体事件, 同时这些弱势群 体有相同的心理共识, 很容易以集体化或规模 化的形式宣泄不满, 使事件不断升级放大。从 而导致了风险第四轮放大, 使得城市特大内涝 灾害演化为个体事件。

\section{5. 基于四维放大模型和演化机理的城市特大 内港灾害社会风险应对建议}

基于以上研究分析, 可知城市特大内涝灾 害社会风险与一般风险事件有着相似之处, 但 又具有独特的放大途径、机制和演化机理, 应 区别于其他非常规风险事件的治理措施。根据 放大机制和演化机理, 我们提出应对城市特大 内涝灾害社会风险的三条建议。

（1）建立灾害风险信息披露机制与新闻 发言人制度

城市特大内涝灾害往往成为社会关注的焦 点, 有关灾害的各种信息经过媒体、网络等“放 大站” 的加工会导致风险的放大与演化。做好 灾害事件的新闻报道和信息披露关系到社会稳 定和人心安定以及人民群众对政府的信任。因 此, 灾害政府部门要及时披露灾害损失情况、 救援等信息。同时, 政府救灾能力遭到质疑时, 
政府部门发言人要及时表态, 将真相及时告知 公众, 对于歪曲性报道或谣言及时予以澄清, 正确引导與论, 防止各种谣言带来的社会秩序 混乱。另外, 有些媒体为了吸引大众眼球, 故 意用一些具有象征意义的标题，各种报道之间 存在不一致性, 为了消除信息不确定性与争议 性给受灾群众带来的恐慌, 政府部门要建立“新 闻发言人”制度，完善新闻发布机制，及时发 布权威信息。

（2）构建城市特大内港灾害社会风险预

\section{警与响应平台}

城市特大内涝灾害社会风险是由个体事件 逐步演化为群体性事件进而演化为社会风险。 在这个演化的过程中会有一些风险信息, 一旦 爆发会给社会稳定与秩序带来严重威胁。因此 有效阻断城市特大内涝灾害社会风险要就要及 时预警, 建立政府部门牵头, 民政局、卫生局、 公安、武警部门配合的社会风险预警与响应平 台, 及时捕捉灾害发生后酝酿的各种风险信息, 根据风险信息的特征将具体化解工作落实具体 部门, 各部门联动预防、预警, 阻断其演化途 径, 防止应急中出现漏洞。同时, 鼓励社会群 众举报周围隐藏的风险事件, 并及时处理、消 解误会和矛盾, 将事件消除在萌芽状态, 创造 群众与政府相互信任的氛围。

（3）完善救援保障体系, 鼓励社会参与 救援和灾害保险的实施

由浙江余姚的案例可以看出, 灾害发生后 群体做出非理性行为的根本原因在于灾害造成 的食物短缺、安置困难等有关衣食住行的基本 生活问题得不到解决, 尤其是一些弱势群体。 因此, 灾后政府要及时调拨大量救援物资救援, 平时就要完善救援保障体系, 给弱势群体创造 良好的就业环境和经济补助, 提高其防灾减灾 抵御风险的能力。此外, 由于政府的能力和资 源是有限的, 还应鼓励社会成员参与到救灾中, 也可以降低企业的一部分税收刺激企业为灾区 捐款或在灾区开发项目。同时, 鼓励企业和个 人在平时购买灾害保险, 减小灾害带来的损失, 提高人们应对灾害的能力。

\section{6. 结论}

城市特大内涝灾害不仅会造成人员伤亡、 环境破坏等直接伤害, 在社会、政治、经济因
素下会不断放大演化, 对社会稳定与秩序构成 潜在威胁。本文根据风险社会放大理论构建了 中国城市特大内涝灾害社会风险四维放大模 型, 探讨了城市特大内涝灾害社会风险四级放 大机制和三阶段演化过程，得到信息传播、公 众反应、政府信任度和社会转型风险导致了城 市特大内涝风险的放大, 并且遵循由自然属性 的内港灾害演化为个体风险事件、群体性事件、 社会风险的机理。并用浙江余姚城市特大内涝 社会风险案例对提出的模型与演化机理进行局 部验证, 同时提出了信息披露、社会风险预警 和社会保障体系建立的社会风险应对建议, 为 城市特大内涝灾害社会风险的进一步研究提供 了借鉴。但是由于城市特大内涝灾害社会风险 的演化与放大过程是动态的, 需要在微观和宏 观中进行分析, 缺乏丰富的数据验证。因此, 在未来研究中需要收集大量的数据资料将以上 研究进行量化研究和仿真模拟。

\section{参考文献}

[1] 谢映霞. 从城市内港灾害频发看排水规划 的发展趋势. 城市规划,2013,(2):45-50.

[2]救灾司.民政部国家减灾办发布 2013 年全国 自然灾害基本情况[EB/OL]. [2014-02-20]. http://jzs.mca.gov.cn/article/zjz/gzdt/201401/ 20140100572862.shtml.

[3] 徐选华,薛敏,王春红.基于改进 ISR 压力模 型的自然灾害社会心理风险识别研究. 灾 害学,2014,29(1):1-7.

[4] Tierney K J. From the margins to the mainstream? Disaster research at the crossroads. Annu. Rev. Sociol., 2007, 33: 503-525.

[5] Nel P, Righarts M. Natural disasters and the risk of violent civil conflict. International Studies Quarterly, 2008, 52(1): 159-185.

[6] Omelicheva M Y. Natural disasters: triggers of political instability? International Interactions, 2011, 37(4): 441-465.

[7] Hsiang S M, Burke M. Climate, conflict, and social stability: what does the evidence say? Climatic Change, 2014, 123(1): 39-55.

[8] Scheffran J, Brzoska M, Brauch H G, et al. Climate change, human security and violent 
Risk Analysis and Crisis Response in Big Data Era (RAC-16)

conflict[M]. New York: Springer, 2012.

[9] 朱思诚,任希岩.关于城市内涝问题的思考. 行政管理改革,2011,(11):62-66.

[10] 任希岩,谢映霞,朱思诚等.在城市发展转型 中重构——关于城市内涝防治问题的战略 思考.城市发展研究,2012,19(6):71-77.

[11] Wei Zhang, Yingjun Hu, et al. Research on Urban Waterlogging Disaster Risk Assessment Based on ARCGIS and MIKE FLOOD - A Case Study on Shijiazhuang . Journal of Risk Analysis and Crisis Response, 2015,5(4),226-233.

[12] 彭远春. 我国转型期的社会风险及其防范. 理论月刊, 2009, 8:102-104.

[13] 李航.我国转型期弱势群体社会风险管理 探析[D].成都:西南财经大学,2005.

[14] Kasperson R E, Renn O, Slovic P, et al. The social amplification of risk: A conceptual framework. Risk analysis, 1988, 8(2): 177-187.

[15] Poumadere M,Mays C,Mer SL.The 2003 heat wave in France: Dangerous climate change here and now. Risk Analysis, 2005,25(6): 1483-1494.

[16] Burgess A. Media,risk,and absence of blame for"Acts of God":Attenuation of the European volcanic ash cloud of 2010.Risk Analysis,2012,32(10):1693-1702.

[17] Brenkert-Smith H,Dickinson KL,Champ PA,et al.Social Amplification of Wildfire Risk: The Role of Social Interactions and Information Sources.Risk Analysis, 2013, 33(5):800-817.

[18] 易承志.社会组织在应对大都市突发事件 中的作用及其实现机制. 中国行政管 理,2014,2:60-64.

[19] 盛明科,郭群英.公共突发事件联动应急的 部门利益梗阻及治理研究. 中国行政管 理.2014,3:38-42.

[20] Scheffran J, Brzoska M, Kominek J, et al. Climate change and violent conflict. Science (Washington), 2012, 336(6083): 869-871.

[21] Siegrist M, Cvetkovich G. Perception of hazards: The role of social trust and knowledge. Risk Analysis, 2000, 20(5): 713-719.

[22] Espluga J, Gamero N, Prades A, Sola R. El papel de la confianza en los conflictos socio ambientales. Política y sociedad, 2009, 46(1-2): 225-273.

[23] Wachinger G,Renn O,Begg C,et al.The Risk Perception Paradox-Implications for Governance and Communication of Natural Hazards.Risk Analysis, 2013, 33(6): 1049-1065.

[24] Bichard E, Kazmierczak A. Are homeowners willing to adapt to and mitigate the effects of climate change? . Climate Change, 2012,112: 633-654.

[25] 刘冰,薛澜. “管理极端气候事件和灾害风 险特别报告”对我国的启示. 中国行政管理, 2012,3:92-95.

[26] 深港在线. 浙江余姚水灾严重致 80 多万人 受灾 $70 \%$ 城区被淹乡镇断电缺粮 [EB/OL].[2014-02-20] http://www.szhk.com/ 2013/10/09/282856087743988.html.

[27] 深港在线. 男子余姚水灾时带头哄抢救援 物资获刑 1 年[EB/OL].[2014-02-20] http:// news .szhk.com/2014/02/20/2828675847192 21.html.

[28] 赵琬仪. 抗议政府救灾不力 浙余姚数千市 民与警冲突 [EB/OL].[2014-02-20] http:// blog.sina.com.cn/s/blog_404dfe7d0101np0f. html.

[29] 新京报.物资缺物价涨 余姚被质疑救灾不 力 $[\mathrm{EB} / \mathrm{OL}]$. [2014-02-20] http://www.bjnews. com.cn/feature/2013/10/10/286645.html.

[30] 罗成琳, 李向阳. 突发性群体事件及其演化 机理分析.中国软科学,2009,6:163-177.

[31] 刘燕,万欣荣.中国社会转型的表现、特点 与缺陷.社会主义研究,2011,4:5-9. 